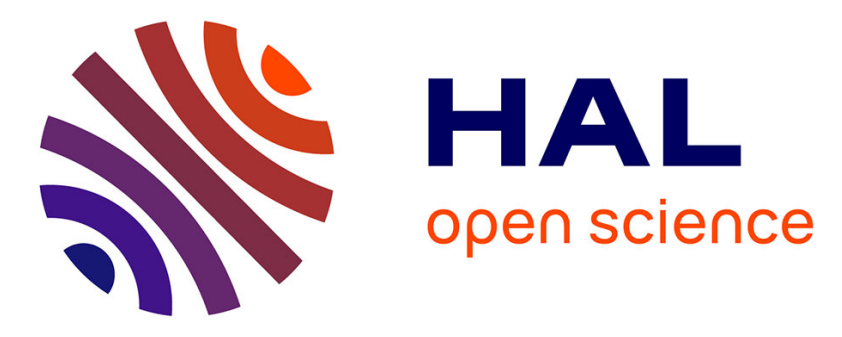

\title{
Nafion-Radical Hybrid Films on Carbon Nanotube Transistors for Monitoring Antipsychotic Drug Effects on Stimulated Dopamine Release
}

\author{
Viet Anh Pham Ba, Dong-Guk Cho, Seunghun Hong
}

\section{To cite this version:}

Viet Anh Pham Ba, Dong-Guk Cho, Seunghun Hong. Nafion-Radical Hybrid Films on Carbon Nanotube Transistors for Monitoring Antipsychotic Drug Effects on Stimulated Dopamine Release. ACS Applied Materials \& Interfaces, 2019, 11 (10), pp.9716-9723. 10.1021/acsami.8b18752 . hal02187852

\section{HAL Id: hal-02187852 \\ https://hal.science/hal-02187852}

Submitted on 18 Jul 2019

HAL is a multi-disciplinary open access archive for the deposit and dissemination of scientific research documents, whether they are published or not. The documents may come from teaching and research institutions in France or abroad, or from public or private research centers.
L'archive ouverte pluridisciplinaire HAL, est destinée au dépôt et à la diffusion de documents scientifiques de niveau recherche, publiés ou non, émanant des établissements d'enseignement et de recherche français ou étrangers, des laboratoires publics ou privés. 
This document is confidential and is proprietary to the American Chemical Society and its authors. Do not copy or disclose without written permission. If you have received this item in error, notify the sender and delete all copies.

\section{Nafion-Radical Hybrid Films on Carbon Nanotube Transistors for Monitoring Antipsychotic Drug Effects on Stimulated Dopamine Release}

\begin{tabular}{|r|l|}
\hline Journal: & ACS Applied Materials \& Interfaces \\
\hline Manuscript ID & am-2018-18752r.R1 \\
\hline Manuscript Type: & Article \\
\hline Date Submitted by the \\
Author: & 07-Jan-2019 \\
\hline Complete List of Authors: & $\begin{array}{l}\text { Pham Ba, Viet Anh; Seoul National University, Department of Physics } \\
\text { and Astronomy } \\
\text { Cho, Dong-guk; Seoul National University, Department of Physics and } \\
\text { Astronomy } \\
\text { Hong, Seunghun; Seoul National University, Physics }\end{array}$ \\
\hline
\end{tabular}

\section{SCHOLARONE ${ }^{\text {M }}$ Manuscripts}




\title{
Nafion-Radical Hybrid Films on Carbon Nanotube Transistors for
}

\section{Monitoring Antipsychotic Drug Effects on Stimulated Dopamine}

\author{
Release \\ Viet Anh Pham Ba ${ }^{\dagger}$, Dong-guk Cho ${ }^{\dagger}$, Seunghun Hong ${ }^{\dagger, \S, *}$ \\ $\dagger$ Department of Physics and Astronomy, and Institute of Applied Physics, Seoul National \\ University, Seoul 08826, South Korea \\ $\S$ Department of Biophysics and Chemical Biology, Seoul National University, Seoul 08826, \\ South Korea
}

KEYWORDS: Dopamine, Pimozide, ABTS, Nafion, Carbon nanotube field-effect transistor 


\begin{abstract}
We developed floating electrode-based carbon nanotube biosensors for the monitoring of antipsychotic drug effects on the dopamine release from PC12 cells under potassium stimulation. Here, carbon nanotube field-effect transistors with floating electrodes were functionalized with ABTS ${ }^{\bullet}$ radicals by nafion films. This method allows us to build selective biosensors for dopamine detection with a detection limit down to $10 \mathrm{nM}$ even in the presence of other neurotransmitters such as glutamate and acetylcholine, resulting from the selective interaction between $\mathrm{ABTS}^{\bullet}$ radicals and dopamine. The sensors were also utilized to monitor the real-time release of dopamine from PC12 cells upon the stimulation of highconcentrated potassium solutions. Significantly, the antipsychotic effects of pimozide on the dopamine release from potassium-stimulated $\mathrm{PC} 12$ cells could also be evaluated in a concentration-dependent manner by using the sensors. The quantitative and real-time evaluation capability of our strategy should provide a versatile tool for many biomedical studies and applications.
\end{abstract}




\section{INTRODUCTION}

Dopamine is one of important neurotransmitters, which regulates a wide variety of functions in the central nervous system. Dopamine dysfunctions in the nervous system are concerned various neurological symptoms such as Parkinson's disease and schizophrenia. ${ }^{1,2}$ It has been reported that the concentration changes of potassium ions $\left(\mathrm{K}^{+}\right)$in the brain may induce neurological disorders including the release of neurotransmitters as dopamine. ${ }^{3,4}$ Therefore, the real-time monitoring of the $\mathrm{K}^{+}$-evoked dopamine release from neural cells should be important for the understanding of dopaminergic dysfunctions. Moreover, the primary therapy of schizophrenia is based on the regulation of dopaminergic functions by antipsychotic drugs. Previously, it was reported that antipsychotic drugs inhibited dopamine receptor activities and reduced $\mathrm{K}^{+}$-evoked dopamine release., ${ }^{2,5}$ Thus, one method to monitor the efficacy of antipsychotic drugs can be the monitoring of the dopamine release from drug-pretreated cells under $\mathrm{K}^{+}$-stimulation.

Conventional methods like high-performance liquid chromatography (HPLC), luminescent methods, and electrochemical techniques have been utilized to quantify dopamine release in living systems and evaluate the efficacy of antipsychotic drugs. ${ }^{4-13}$ However, these techniques have their own limitations. For example, HPLC can be complex and costly. Fluorescent methods require time-consuming preparation, and furthermore, the stability of dyes often degrade over time. For electrochemical methods, electrodes can be contaminated by the products of electrochemical reactions or agents in an ambient environment, resulting in the difficulty of data estimation. Moreover, the detection limit of common electrochemical techniques was only at a micromolar level. ${ }^{9-14}$ On the other hand, field-effect transistor (FET) devices have shown distinct advantages, and they have been extensively used to detect dopamine 
in various environments. ${ }^{15-18}$ However, they were not utilized to evaluate the efficacy of actual antipsychotic drugs as well as real-time cellular measurements. Recently, many reports have shown the successful development of carbon nanotube (CNT)-based FET devices for the detection of biomaterials. ${ }^{19-23}$ It indicates that a CNT-FET device functionalized with compatible materials could be used as an effective tool for the biomaterial detection and drug screening.

Herein, we report a nafion-radical hybrid film on a floating electrode-based carbon nanotube sensor to monitor the effects of an antipsychotic drug, pimozide, on the dopamine release from living cells. In this work, a floating electrode-based CNT-FET device was coated by a nafion film containing 2,2'-azino-bis(3-ethylbenzothiazoline-6-sulfonic acid) (ABTS*) radicals to build a selective biosensor for the detection of dopamine. In aqueous solution, ABTS' radicals can selectively react with dopamine, which was detected by underlying sensors for selective sensing. This sensor can selectively monitor the variation of dopamine concentrations down to $10 \mathrm{nM}$ level and distinguish dopamine from other neurotransmitters. We demonstrated the realtime monitoring of $\mathrm{K}^{+}$-evoked dopamine release from $\mathrm{PC12}$ cells using our sensors. Significantly, the sensors were utilized to evaluate the effects of pimozide on the dopamine release of $\mathrm{K}^{+}$-stimulated PC12 cells. This is a selective and sensitive sensor which can be utilized for versatile biological and medical applications.

\section{RESULTS AND DISCUSSION}

\subsection{Characteristics of NRC sensors}

Figure 1 illustrates the real-time monitoring procedure of dopamine release from living PC12 cells by using a nafion-radical hybrid film-based carbon nanotube (NRC) sensor. First, CNT-FET devices with floating electrodes were fabricated as described previously (Figure 1- 
i). ${ }^{19,20,23}$ Briefly, CNTs were selectively adsorbed on a $\mathrm{SiO}_{2}$ substrate, followed by the fabrication of source and drain electrodes $(\mathrm{Pd} / \mathrm{Au}, 10 \mathrm{~nm} / 30 \mathrm{~nm})$ via a thermal deposition and a lift-off process. After that, the source and drain electrodes were insulated by a photoresist-based passivation layer to eliminate leakage currents during sensing experiments in an aqueous environment. A nafion solution containing $\mathrm{ABTS}^{\bullet}$ radicals was directly dropped on the floating electrodes-based CNT-FET device. Then, the device was dried in a nitrogen atmosphere to form a stable and thin film upon the device. It was previously reported that negatively charged nafion layers could attract positively charged molecules, and, thus, nafion has been used as a catalytic layer to attract dopamine near a sensor surface. ${ }^{12-14}$ In our work, a nafion film not only acts as a catalytic layer but also as a matrix holding ABTS $^{\bullet}$ radicals to enhance the sensitivity of our sensor. The redox reactions between dopamine and ABTS ${ }^{\bullet}$ radicals generate hydrogen ions $\left(\mathrm{H}^{+}\right)$ which can diffuse in the nafion film, increase the density of positive charges near the transducer of CNT-FET sensors, and eventually change the electrical currents in the sensor. Using this method, we could build NRC sensors for the selective detection of dopamine in aqueous solutions (Figure 1-ii). It also should be mentioned that nafion has been extensively utilized as a part of sensors operating in aqueous solutions with different chemical substances including dopamine and PBS buffer, implying that the nafion was stable after our dopamine sensing experiments in PBS buffer. ${ }^{12-14}$ For the measurements of dopamine release from living cells, PC12 cells were cultured in a culture dish as reported previously (Figure 1-iii). ${ }^{24}$ Then, a PC12 cell suspension was introduced on an NRC sensor using a pipette (Figure 1-iv), and the cells were stimulated by high-concentrated $\mathrm{K}^{+}$solutions for the release of dopamine (Figure 1-v). The release of dopamine was monitored using our NRC sensors. 
The quality of an NRC sensor was checked by imaging the surface structure of the sensor. Figure 2a-i shows the optical image of an NRC sensor including five floating electrodes. The optical image was obtained by using an optical microscope (XY-MRT, Sunny) equipped with a CCD camera (SDC-415S, Samsung). The image shows well-defined electrodes with the $10 \mu \mathrm{m} \times$ $60 \mu \mathrm{m}$ dimension for each floating electrode. Furthermore, the topography image (Figure 2a-ii) of an NRC sensor was taken by an atomic force microscope (AFM) system (MFP-3D, Asylum Research) in a tapping mode with a scan rate of $0.7 \mathrm{~Hz}$. The AFM image shows a uniform nafion layer on the floating electrode area of the NRC sensor. The thickness of the nafion film could be estimated as $200 \mathrm{~nm}$ using the AFM topography image on the boundary of the film (Figure S1 in Supporting Information).

To confirm the functionalization of an NRC sensor by ABTS radicals, we performed the

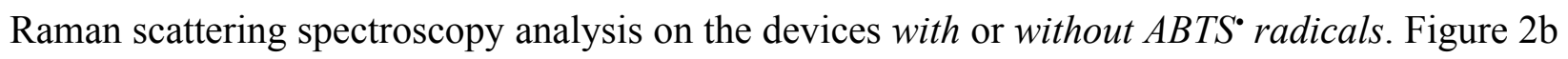
shows the Raman spectra of an NRC sensor, a floating electrode-based CNT-FET device coated with a pure nafion layer without $A B T S^{\bullet}$ radicals (NCF sensor), and a bare CNT-FET device with floating electrodes. Raman spectra were measured at CNT channel areas by using a Raman spectroscope (XperRam 200, Nanobase) in a single mode. The Raman spectrum (black line) of CNTs on a bare device exhibits a rather large G-band peak $\left(1588 \mathrm{~cm}^{-1}\right)$ as well as a much smaller D-band peak $\left(1314 \mathrm{~cm}^{-1}\right)$, indicating the small number of defects in used semiconducting CNTs. ${ }^{25,26}$ We also measured a UV-VIS-NIR spectrum from the bare CNT devices to evaluate the quality of the CNT channels in our sensors (Figure S2 in Supporting Information). The result clearly shows the peaks at wavelengths of 581 and $1012 \mathrm{~nm}$, which can be attributed to $(6,5)$ semiconducting CNTs as reported previously. ${ }^{26}$ These results support the high quality of our semiconducting CNT channels in our devices. The Raman spectroscopy measurements of the 
devices on floating electrode areas are also shown in Supporting Information (Figure S3). The Raman spectra of the NRC sensor exhibit vibration bands at characteristic wavenumbers such as 690, 862, 1046, 1201, 1255 and $1592 \mathrm{~cm}^{-1}$ which can be associated with ABTS ${ }^{\bullet}$ radicals as reported previously. ${ }^{27,28}$ It indicates the presence of ABTS ${ }^{\bullet}$ radicals in the nafion layer on the NRC sensor. This result clearly shows that our device was successfully functionalized with a nafion-radical hybrid film.

The electrical characteristics of our NRC sensor was investigated by applying a liquid gate bias $\left(V_{l g}\right)$ to the NRC sensor in a phosphate buffered saline solution. Figure 2c shows the typical liquid gating effect of an NRC sensor. Here, a gate bias was swept from $-1 \mathrm{~V}$ to $1 \mathrm{~V}$ while a source-drain bias voltage was maintained at $0.1 \mathrm{~V}$. The curve shows a decreasing sourcedrain current with an increasing gate bias, which is a typical behavior for $p$-type semiconductors. Importantly, the drastic change of source-drain currents in the small change of a gate bias voltage indicates the high sensitivity of the NRC sensor.

\subsection{Discrimination of dopamine by NRC sensors}

Figure 3a depicts a schematic diagram showing the sensing mechanism of an NRC sensor for dopamine molecules. Once dopamine molecules approach to the surface of an NRC sensor, redox reactions between dopamine molecules and ABTS radicals occur (Scheme S1 in Supporting Information). ${ }^{13,29,30}$ These redox reactions generate $\mathrm{H}^{+}$which can interact with the sulfonate groups of nafion, resulting in the increase of positive potentials in a nafion film on the NRC sensor. Here, nafion not only acts as an ion binder and a signal transporter, but also plays a role as an insulator to prevent the effects of an ambient environment on the sensor. Note that since CNT channels in our sensors exhibited $p$-type characteristics, the increase of positive 
potentials would cause the decrease of their conductance (Figure 2c). Thus, once a dopamine solution is added on an NRC sensor, the increased positive potential in the nafion film upon the device causes the decreased electrical conductance.

Figure $3 \mathrm{~b}$ shows the real-time measurement result of an electrical current in an NRC sensor during the additions of dopamine solutions at various concentrations in the range of 10 $\mathrm{nM}$ to $100 \mu \mathrm{M}$. The graph shows a sharp decrease in the source-drain current after the addition of a dopamine solution, and then the electrical current gradually stabilizes. However, there were no significant changes in an electrical current through a bare floating electrode-based CNT-FET device during the additions of dopamine solutions (Figure S4 in Supporting Information). Note that the NRC sensor exhibited current changes much larger than noise amplitudes even at $10 \mathrm{nM}$. These results indicate that our method can discriminate various concentration dopamine solutions with the detection limit of $10 \mathrm{nM}$. As a control experiment, we measured the response of an NCF sensor to dopamine (Figure S5 in Supporting Information). The results show negligible current changes less than $3 \%$ by the dopamine with the concentrations up to $100 \mu \mathrm{M}$, which is much smaller than the signals by our NRC sensors with ABTS' radicals. The response of the NCF sensor may be attributed to the electrostatic interactions between dopamine molecules and nafion film, which may also cause unexpected effects on the responses of NRC sensors to dopamine ${ }^{13-15}$. However, the control experiment results show that these effects are not significant for dopamine concentrations up to $100 \mu \mathrm{M}$. It also should be mentioned that the response time of our sensor was $\sim 25$ seconds (Figure $3 b$ ), which was rather fast compared with previous dopamine sensors including nafion layers (Table S1 in Supporting Information). Previous works showed that the diffusion time of $\mathrm{H}^{+}$in a nafion film depended on the film thickness, which may delay sensor responses. ${ }^{31}$ However, in our case, the response time of the 
sensor was rather fast compared with previous works and enough for practical applications, indicating the time delay by the diffusion in the nafion film was not a significant problem in our sensors (Table S1 in Supporting Information). Moreover, the quick responses of the NRC sensor imply that our sensors can be used for real-time monitoring applications.

Figure $3 \mathrm{c}$ shows the normalized conductance changes of our sensors exposed to dopamine solutions with difference concentrations $\left(C_{D A}\right)$. The dose-response curve indicated a wide dynamic range $(10 \mathrm{nM}-100 \mu \mathrm{M})$ where our sensors can be used for monitoring dopamine levels. Significantly, the equilibrium constant $K_{e q}$ of redox reactions between ABTS radicals and dopamine could be estimated by fitting data with Langmuir thermal equation given by ${ }^{19,32}$

$$
\left|\Delta G / G_{0}\right|=\frac{\left|\Delta G / G_{0}\right|_{\max } \times C_{D A}}{1 / K_{e q}+C_{D A}}
$$

where $\left|\Delta G / G_{0}\right|$ and $\left|\Delta G / G_{0}\right|_{\max }$ represent the absolute value of a relative conductance change and its maximum absolute value. Based on this model, the value of $K_{e q}$ was estimated as $10^{5.08 \pm 0.21}$. Previous reports showed the formal standard redox potential $\left(E^{0^{\prime}}\right)$ values of ABTS and dopamine are $0.47 \mathrm{~V}$ (vs $\mathrm{Ag} / \mathrm{AgCl})$ and $0.75 \mathrm{~V}$ (vs SHE), respectively. ${ }^{29,30}$ The equilibrium constant $K_{e q}$ of the redox reaction calculated based on these $E^{0^{\prime}}$ values is $10^{5.33}$ which is similar to the value estimated by our method.

To investigate the selectivity of our NRC sensor, we measured electrical currents through an NRC sensor during the additions of other neurotransmitters such as glutamate and acetylcholine which can be released with dopamine from stimulated cells. ${ }^{33}$ Figure $3 \mathrm{~d}$ shows the electrical current changes in an NRC sensor during the additions of various neurotransmitters. The graph indicates that only the addition of dopamine caused an electrical current decrease, while the additions of glutamate and acetylcholine did not affect the electrical current in the 
NRC sensor. These results show that our NRC sensor could be used to selectively detect dopamine even in a mixed solution. Note that the responses of NRC sensors come from the interactions between ABTS ${ }^{\bullet}$ radicals and phenolic hydroxyl $(\mathrm{OH})$ groups. Therefore, our sensors can be applied to detect a broad range of biomolecules with phenolic $\mathrm{OH}$ groups such as dopamine, uric acid, and ascorbic acid. In our work, the NRC sensors were used to monitor dopamine released from cells stimulated by $\mathrm{K}^{+}$. In this case, $\mathrm{K}^{+}$-stimulated cells are reported to release neurotransmitters such as dopamine, glutamate and acetylcholine, and dopamine is the only chemical substance with phenolic $\mathrm{OH}$ groups.,11,24,33 Thus, we performed the selective sensing experiments with other neurotransmitters, showing that our method can be used to selectively detect dopamine out of all neurotransmitters released from $\mathrm{K}^{+}$-stimulated cells (Figure 3d).

\subsection{Real-time monitoring of $\mathrm{K}^{+}$-evoked dopamine release from PC12 cells using NRC sensors}

Figure 4a depicts the mechanism for the responses of an NRC sensor to dopamine molecules released from a PC12 cell. Once the PC12 cell is stimulated by a high-concentrated $\mathrm{K}^{+}$ solution, the depolarization of the plasma membrane may induce the influx of calcium ions $\left(\mathrm{Ca}^{2+}\right)$ into the cell through voltage-dependent calcium channels (VDCCs) and the release of intracellular $\mathrm{Ca}^{2+}$ stores. The increase of intracellular $\mathrm{Ca}^{2+}$ evokes the neurotransmitter release from the cell. Besides, it was reported that stimulations by high-concentrated $\mathrm{K}^{+}$solutions preferentially induced the release of dopamine by exocytosis. ${ }^{4,11,24}$ After that, released dopamine molecules diffuse to a nafion film and interact with ABTS ${ }^{\circ}$ radicals in the nafion film on an NRC sensor. This interaction generates $\mathrm{H}^{+}$which will diffuse in the nafion film, leading to the 
decrease of the electrical current as described previously (Figure 3a). Thus, our NRC sensor could be used to quantitatively monitor dopamine release from living cells. Furthermore, in our experiments, PC12 cells can be stored during the sensing processes without being cultured on an NRC sensor, indicating rather simple sensing processes compared with previous works. ${ }^{17}$

Figure $4 \mathrm{~b}$ shows the real-time changes of electrical currents in an NRC sensor by dopamine release from PC12 cells. Here, the PC12 cells were stimulated by high-concentrated $\mathrm{K}^{+}$solutions (containing $2.5 \mathrm{mM} \mathrm{Ca}^{2+}$ ) to release dopamine by exocytosis. The graph shows that the addition of a cell suspension did not affect the electrical currents of the NRC sensor. In contrast, the additions of high-concentrated $\mathrm{K}^{+}$solutions caused the decrease of its electrical current, indicating that PC12 cells released a significant amount of dopamine to the buffer solution. We also measured the electrical current changes of NRC sensors in the absence of PC12 cells during the additions of different $\mathrm{K}^{+}$solutions, which did not show any significant current changes (Figure S6 in Supporting Information). These results clearly show that our sensors can selectively monitor the $\mathrm{K}^{+}$-evoked dopamine release from live cells.

Figure $4 \mathrm{c}$ shows a correlation between the concentrations of released dopamine and the concentrations of $\mathrm{K}^{+}$solutions. The dose-response curves of our sensors (Figure 3c) were used to calculate the concentration of dopamine released from PC12 cells. The dopamine release was increased significantly when the concentration of $\mathrm{K}^{+}$solutions increased from $20 \mathrm{mM}$ to 160 $\mathrm{mM}$, presumably due to the increase of membrane depolarization as reported previously. ${ }^{4}$ This result shows that the concentration change of extracellular $\mathrm{K}^{+}$may influence neurological functions such as membrane potential maintenance and neurotransmitter transport. ${ }^{3,4}$ Previous works showed that the sensor response could be significantly delayed by the diffusion time of target molecules in solution and in nafion layers. ${ }^{31}$ However, in our experiment, the response 
time was quite quick enough for practical applications. Presumably, due to the small volume of our working solution $(\sim 10 \mu \mathrm{L})$, it did not take a long time for released dopamine to reach the sensor surface. Also, $\mathrm{H}^{+}$generated during the sensing process can diffuse very quickly inside the nafion film with a rather small thickness of $\sim 200 \mathrm{~nm}$, resulting in the quick response of our sensors. On the other hand, it was previously reported that the concentration of a ABTS radical solution $(\mathrm{pH}=7.4)$ decreased by $10 \%$ after 60 min exposure to ambient air, which may cause instability of signals if the sensing experiments last for a long time period. ${ }^{34}$ However, the rather fast response time of our sensors allowed us to finish most of the sensing experiments in less than ten minutes (Figure 4b). Thus, the effect by the degradation of ABTS radicals is expected to be minimal in our experiments. Importantly, these results imply that our method can be used to quantitatively monitor the real-time release of biomaterials in living systems. Moreover, these results show that our method based on CNT FET devices exhibited several advantages over conventional methods (Table S1 in Supporting Information). For example, our NRC sensors exhibited a higher sensitivity and faster responses than most of previous sensors and, thus, can be utilized for the measurement of real samples such as cells.

\subsection{Monitoring antipsychotic effects on $\mathrm{K}^{+}$-evoked dopamine release from PC12 cells by NRC sensors}

Since the abnormal changes of dopamine levels in nervous cells is involved in neurological diseases, the therapeutic methods have been suggested using dopaminergic drugs. For example, pimozide is an antipsychotic, which has been marketed to care for patients with schizophrenia. ${ }^{35}$ Since the mechanism of dopamine release from PC12 cells is similar to that from neurons, PC12 cells have been extensively used for studies regarding antipsychotics. ${ }^{5,36}$ 
Figure 5a illustrates the mechanism of the effect by pimozide for the synthesis and accumulation of dopamine in the cytosols of PC12 cells. Once pimozide molecules bind to dopamine D2 receptors (D2Rs) on a plasma membrane, their antagonistic activity inhibits the production of dopamine and the transport of dopamine vesicles. ${ }^{5,37}$ Therefore, pimozide can induce the reduction of dopamine release from neurons and PC12 cells. Thus, by measuring the reduction of dopamine release with antipsychotic drugs via our NRC sensors, we can quantitatively evaluate the effects of antipsychotic drugs on the dopamine release.

Figure $5 \mathrm{~b}$ shows the dependence of $\mathrm{K}^{+}$-evoked dopamine release from PC12 cells on the concentrations of pimozide. In these experiments, PC12 cells were pretreated with pimozide with different concentrations of $0.01-10 \mu \mathrm{M}$ for $24 \mathrm{~h}$, followed by the stimulation of $80 \mathrm{mM} \mathrm{K}^{+}$ solutions. Post-stimulated solutions were then harvested and introduced onto our NRC sensors to evaluate the released dopamine levels. The responses show that PC12 cells expressed decreasing dopamine release with higher concentrations of pimozide. It clearly shows that pimozide acted as an antagonist on D2Rs, resulting in the reduced $\mathrm{K}^{+}$-evoked dopamine release from PC12 cells. Also, these results are consistent with reported results. ${ }^{5}$ This indicates that our NRC sensor could be used as a reliable tool to monitor the effect of dopaminergic drugs as well as other biomedical applications.

\section{CONCLUSIONS}

We successfully demonstrated a biocompatible, simple, and flexible method for the effect evaluation of antipsychotic drugs on dopamine release from PC12 cells upon the stimulation of high-concentrated $\mathrm{K}^{+}$solutions. In this strategy, we modified floating electrode-based CNT-FET devices by a thin nafion film containing ABTS' radicals to build NRC sensors for dopamine 
detection. Using NRC sensors, we could distinguish dopamine in aqueous solutions from the concentration of $10 \mathrm{nM}$ and in the presence of other neurotransmitters, indicating the sensitivity and selectivity of our method. In particular, the dopamine release from PC12 cells stimulated by high-concentrated $\mathrm{K}^{+}$solutions could be quantitatively monitored by our NRC sensors. Moreover, the antipsychotic effects of pimozide on the $\mathrm{K}^{+}$-evoked dopamine release from PC12 cells were also evaluated in a concentration-dependent manner. The biocompatible capability of our method should provide a vital tool and open up various developments in biosensor research and biomedical applications.

\section{EXPERIMENTAL SECTION}

\subsection{Materials}

Semiconducting single-walled carbon nanotubes (CNTs), dopamine hydrochloride, nafion, 2,2'-azino-bis(3-ethylbenzothiazoline-6-sulfonic acid) diammonium salt, potassium persulfate, L-glutamic acid monosodium salt hydrate, acetylcholine chloride, pimozide and other chemical reagents were purchased from Sigma-Aldrich and used as received. CNTs had the diameter of $0.7-1.1 \mathrm{~nm}$ and the length of $300-2300 \mathrm{~nm}$. PC12 cells were purchased from the Korean Cell Line Bank (KCLB).

\subsection{Fabrication of CNT-FET Devices}

First, CNTs were dispersed in 1,2-dichlorobenzene via an ultrasonication for $5 \mathrm{~h}$. The concentration of a CNT solution was $0.05 \mathrm{mg} / \mathrm{mL}$. Then, an octadecyltrichlorosilane selfassembled monolayer with nonpolar terminal groups was patterned on $\mathrm{SiO}_{2}$ substrate $(3000 \AA)$. For the selective adsorption of CNTs, the substrate was placed in the CNT solution for $10 \mathrm{sec}$ 


\subsection{Preparation of NRC Sensors}

A nafion solution $\left(0.5 \%\right.$ in ethanol) containing $1.4 \mathrm{mM} \mathrm{ABTS}$ and $0.49 \mathrm{mM} \mathrm{K}_{2} \mathrm{~S}_{2} \mathrm{O}_{8}$ was mixed in an ultrasonic bath for $30 \mathrm{~min}$ to form a coating solution. Afterward, $2 \mu \mathrm{L}$ of the coating solution containing $\mathrm{ABTS}^{\bullet}$ radicals was directly dropped on a floating electrodes-based CNTFET device. Then, the device was dried in a nitrogen atmosphere at room temperature to form a stable and thin film upon the device. Using this method, we could build NRC sensors for the selective detection of dopamine in aqueous solutions (Figure 1-ii).

\subsection{Surface Imaging Procedures of NRC Sensors}

The optical image of an NRC sensor was taken by a microscope (XY-MRT, Sunny) equipped with a $20 \times$ objective lens and a CCD camera (SDC-415S, Samsung). The topography of a sensor surface was measured by using an AFM system (MFP-3D, Asylum Research) in a tapping mode with a scan rate of $0.7 \mathrm{~Hz}$. Raman scattering spectra were obtained in a backscattering configuration using a Raman microprobe (XperRam 200, Nanobase) in a single mode with the spectral resolution of $4 \mathrm{~cm}^{-1}$. A $532 \mathrm{~nm}$ solid laser was used as an excitation 
source with the laser power of $\sim 2 \mathrm{~mW}$ and the beam diameter of $\sim 50 \mu \mathrm{m}$ on the surface of samples.

\subsection{Measurements of the Liquid Gating Effect of NRC Sensors}

A gold electrode was utilized to apply a liquid gate bias $\left(V_{l g}\right)$ on an NRC sensor through a phosphate buffered saline (PBS) solution. For liquid gating effect measurements, a gate bias was swept from -1 to $1 \mathrm{~V}$ while a source-drain bias was maintained with $0.1 \mathrm{~V}$. The source-drain current of the sensor was measured by a semiconductor characterization system (Keithley, 4200, USA).

\subsection{Sensing Measurements}

For sensing measurements, an NRC sensor was connected to a Keithley 4200 semiconductor analyzer, and a source-drain bias voltage of $0.1 \mathrm{~V}$ was maintained during the measurements. The $9 \mu \mathrm{L}$ droplet of a PBS solution was placed on the sensing region of the NRC sensor, and a source-drain current was monitored in response to the additions of different target materials. In our experiments, the conductance change over the original conductance of sensors $\Delta G / G_{0}$ was used as a sensor signal.

\subsection{Measurements of Dopamine Release from PC12 Cells}

For the measurements of dopamine release from living cells, PC12 cells were cultured in a culture dish as reported previously (Figure 1-iii). ${ }^{24}$ Briefly, PC12 cells were cultured in RPMI 1640 Medium (A10491-01, Gibco) supplemented with horse serum (10\% v/v), fetal bovine serum $(5 \% \mathrm{v} / \mathrm{v})$, penicillin $(100 \mathrm{U} / \mathrm{mL})$, and streptomycin $(100 \mu \mathrm{g} / \mathrm{mL})$ at $37{ }^{\circ} \mathrm{C}$ in a $5 \% \mathrm{CO}_{2}$ 
atmosphere. Before electrical measurements, PC12 cells were washed three times with a PBS solution (DPBS 17-512, Lonza). Then, PC12 cell suspensions in the buffer solution with the density of $1.3 \times 10^{6}$ cells $/ \mathrm{mL}$ were loaded on an NRC sensor (Figure 1-iv). After that, the cells stimulated by high-concentrated $\mathrm{K}^{+}$solutions (containing $2.5 \mathrm{mM} \mathrm{Ca}^{2+}$ ) for dopamine release which was monitored using our NRC sensors (Figure 1-v). The powders of calcium chloride and potassium chloride were dissolved in the PBS solution to prepare stimulated solutions containing $2.5 \mathrm{mM} \mathrm{Ca}^{2+}$ and the different concentrations of $\mathrm{K}^{+}$.

\subsection{Evaluation of antipsychotic drug}

For the evaluation of antipsychotic drug effects, PC12 cells were cultured in $35 \times 10 \mathrm{~mm}$ culture dishes for 2 days. The cells were further incubated in complete growth medium containing pimozide with different concentrations of $0.01-10 \mu \mathrm{M}$ for $24 \mathrm{~h}$. After a medium washout, the cells were stimulated by $80 \mathrm{mM} \mathrm{K}$ solutions (containing $2.5 \mathrm{mM} \mathrm{Ca}{ }^{2+}$ ). Subsequently, the solutions were harvested and introduced onto NRC sensors to evaluate the levels of dopamine release.

\section{ASSOCIATED CONTENT}

\section{Supporting Information}

Scheme for the interaction between dopamine molecules and ABTS• radicals; AFM topography image on the boundary of the nafion film; Additional data for the qualitative evaluation of sensors such as UV-VIS-NIR and Raman spectra; Data about control experiments. 


\section{AUTHOR INFORMATION \\ Corresponding Author \\ *Email: seunghun@snu.ac.kr (S.H.). \\ ORCID}

Viet Anh Pham Ba: 0000-0002-4096-4328

Dong-guk Cho: 0000-0001-8127-7965

Notes

The authors declare no competing financial interest.

\section{ACKNOWLEDGEMENTS}

This work was supported by Bio Nano Health-Guard Research Center funded by the Ministry of Science and ICT (MSIT) of Korea as Global Frontier Project (No. 2013M3A6B2078961). SH also acknowledges the support from the MSIT (Nos. 2014M3A7B4051591, 2017R1A2B2006808) and the European Research Council (ERC) under the European Union's Horizon 2020 research and innovation programme (grant agreement No 682286).

\section{REFERENCES}

(1) Ahlskog, J. E. Beating a Dead Horse: Dopamine and Parkinson Disease. Neurology 2007, 69 (17), 1701-1711.

(2) Howes, O. D.; Egerton, A.; Allan, V.; McGuire, P.; Stokes, P.; Kapur, S. Mechanisms Underlying Psychosis and Antipsychotic Treatment Response in Schizophrenia: Insights from Pet and Spect Imaging. Curr. Pharm. Des 2009, 15 (22), 2550-2559. 
(3) Kofuji, P.; Newman, E. A. Potassium Buffering in the Central Nervous System. Neuroscience 2004, 129 (4), 1045-1056.

(4) Almaraz, L.; Gonzalez, C.; Obeso, A. Effects of High Potassium on the Release of [3H]Dopamine from the Cat Carotid Body in Vitro. J. Physiol. 1986, 379, 293-307.

(5) Matsuo, T.; Izumi, Y.; Wakita, S.; Kume, T.; Takada-Takatori, Y.; Sawada, H.; Akaike, A. Haloperidol, Spiperone, Pimozide and Aripiprazole Reduce Intracellular Dopamine Content in Pc12 Cells and Rat Mesencephalic Cultures: Implication of Inhibition of Vesicular Transport. Eur. J. Pharmacol. 2010, 640 (1-3), 68-74.

(6) Carrera, V.; Sabater, E.; Vilanova, E.; Sogorb, M. A. A Simple and Rapid Hplc-Ms Method for the Simultaneous Determination of Epinephrine, Norepinephrine, Dopamine and 5Hydroxytryptamine: Application to the Secretion of Bovine Chromaffin Cell Cultures. J. Chromatogr. B 2007, 847 (2), 88-94.

(7) Shinohara, H.; Wang, F. Real-Time Detection of Dopamine Released from a Nerve Model Cell by an Enzyme-Catalyzed Luminescence Method and Its Application to Drug Assessment. Anal. Sci. 2007, 23 (1), 81-84.

(8) De Benedetto, G. E.; Fico, D.; Pennetta, A.; Malitesta, C.; Nicolardi, G.; Lofrumento, D. D.; De Nuccio, F.; La Pesa, V. A Rapid and Simple Method for the Determination of 3,4Dihydroxyphenylacetic Acid, Norepinephrine, Dopamine, and Serotonin in Mouse Brain Homogenate by Hplc with Fluorimetric Detection. J. Pharm. Biomed. Anal. 2014, 98, 266-270.

(9) Kahlouche, K.; Jijie, R.; Hosu, I.; Barras, A.; Gharbi, T.; Yahiaoui, R.; Herlem, G.; Ferhat, M.; Szunerits, S.; Boukherroub, R. Controlled Modification of Electrochemical Microsystems with Polyethylenimine/Reduced Graphene Oxide Using Electrophoretic Deposition: Sensing of Dopamine Levels in Meat Samples. Talanta 2018, 178, 432-440. 
(10) Mercante, L. A.; Pavinatto, A.; Iwaki, L. E.; Scagion, V. P.; Zucolotto, V.; Oliveira, O. N., Jr.; Mattoso, L. H.; Correa, D. S. Electrospun Polyamide 6/Poly(Allylamine Hydrochloride) Nanofibers Functionalized with Carbon Nanotubes for Electrochemical Detection of Dopamine. ACS Appl. Mater. Interfaces 2015, 7 (8), 4784-4790.

(11) Abe, H.; Ino, K.; Li, C. Z.; Kanno, Y.; Inoue, K. Y.; Suda, A.; Kunikata, R.; Matsudaira, M.; Takahashi, Y.; Shiku, H.; Matsue, T. Electrochemical Imaging of Dopamine Release from Three-Dimensional-Cultured Pc12 Cells Using Large-Scale Integration-Based Amperometric Sensors. Anal. Chem. 2015, 87 (12), 6364-6370.

(12) Park, J. A.; Kim, B. K.; Choi, H. N.; Lee, W. Y. Electrochemical Determination of Dopamine Based on Carbon Nanotube-Sol-Gel Titania-Nafion Composite Film Modified Electrode. Bull. Korean Chem. Soc. 2010, 31 (11), 3123-3127.

(13) Chih, Y. K.; Yang, M. C. An 2,2'-Azino-Bis(3-Ethylbenzthiazoline-6-Sulfonic Acid)Immobilized Electrode for the Simultaneous Detection of Dopamine and Uric Acid in the Presence of Ascorbic Acid. Bioelectrochemistry 2013, 91, 44-51.

(14) Chen, P. Y.; Vittal, R.; Nien, P. C.; Ho, K. C. Enhancing Dopamine Detection Using a Glassy Carbon Electrode Modified with Mwcnts, Quercetin, and Nafion. Biosens. Bioelectron. 2009, 24 (12), 3504-3509.

(15) Zhang, M.; Liao, C.; Yao, Y.; Liu, Z.; Gong, F.; Yan, F. High-Performance Dopamine Sensors Based on Whole-Graphene Solution-Gated Transistors. Adv. Funct. Mater. 2014, 24 (7), $978-985$.

(16) Salila Vijayalal Mohan, H. K.; An, J.; Zheng, L. Sequence-Dependent Electrical Response of Ssdna-Decorated Carbon Nanotube, Field-Effect Transistors to Dopamine. Beilstein J Nanotechnol 2014, 5, 2113-2121. 
(17) Li, B. R.; Hsieh, Y. J.; Chen, Y. X.; Chung, Y. T.; Pan, C. Y.; Chen, Y. T. An Ultrasensitive Nanowire-Transistor Biosensor for Detecting Dopamine Release from Living Pc12 Cells under Hypoxic Stimulation. J. Am. Chem. Soc. 2013, 135 (43), 16034-16037.

(18) Park, S. J.; Song, H. S.; Kwon, O. S.; Chung, J. H.; Lee, S. H.; An, J. H.; Ahn, S. R.; Lee, J. E.; Yoon, H.; Park, T. H.; Jang, J. Human Dopamine Receptor Nanovesicles for Gate-Potential Modulators in High-Performance Field-Effect Transistor Biosensors. Sci. Rep. 2014, 4, 4342.

(19) Kim, B.; Lee, J.; Namgung, S.; Kim, J.; Park, J. Y.; Lee, M. S.; Hong, S. DNA Sensors Based on Cnt-Fet with Floating Electrodes. Sens. Actuators B 2012, 169, 182-187.

(20) Lee, M.; Jung, J. W.; Kim, D.; Ahn, Y. J.; Hong, S.; Kwon, H. W. Discrimination of Umami Tastants Using Floating Electrode-Based Bioelectronic Tongue Mimicking Insect Taste Systems. ACS Nano 2015, 9 (12), 11728-11736.

(21) Son, M.; Kim, D.; Park, K. S.; Hong, S.; Park, T. H. Detection of Aquaporin-4 Antibody Using Aquaporin-4 Extracellular Loop-Based Carbon Nanotube Biosensor for the Diagnosis of Neuromyelitis Optica. Biosens. Bioelectron. 2016, 78, 87-91.

(22) Pham Ba, V. A.; Cho, D. G.; Kim, D.; Yoo, H.; Ta, V. T.; Hong, S. Quantitative Electrophysiological Monitoring of Anti-Histamine Drug Effects on Live Cells Via Reusable Sensor Platforms. Biosens. Bioelectron. 2017, 94, 707-713.

(23) Pham Ba, V. A.; Han, Y. M.; Cho, Y.; Kim, T.; Lee, B. Y.; Kim, J. S.; Hong, S. Modified Floating Electrode-Based Sensors for the Quantitative Monitoring of Drug Effects on Cytokine Levels Related with Inflammatory Bowel Diseases. ACS Appl. Mater. Interfaces 2018, 10 (20), 17100-17106. 
(24) Kumar, G. K.; Overholt, J. L.; Bright, G. R.; Hui, K. Y.; Lu, H.; Gratzl, M.; Prabhakar, N. R. Release of Dopamine and Norepinephrine by Hypoxia from PC-12 Cells. Am. J. Physiol. 1998, 274 (6 Pt 1), C1592-1600.

(25) Dresselhaus, M. S.; Jorio, A.; Souza Filho, A. G.; Saito, R. Defect Characterization in Graphene and Carbon Nanotubes Using Raman Spectroscopy. Philos Trans A Math Phys Eng Sci 2010, 368 (1932), 5355-5377.

(26) Tunuguntla, R. H.; Chen, X.; Belliveau, A.; Allen, F. I.; Noy, A. High-Yield Synthesis and Optical Properties of Carbon Nanotube Porins. The Journal of Physical Chemistry C 2017, $121(5), 3117-3125$.

(27) Garcia-Leis, A.; Jancura, D.; Antalik, M.; Garcia-Ramos, J. V.; Sanchez-Cortes, S.; Jurasekova, Z. Catalytic Effects of Silver Plasmonic Nanoparticles on the Redox Reaction Leading to $\mathrm{ABTS}^{\bullet+}$ Formation Studied Using Uv-Visible and Raman Spectroscopy. Phys. Chem. Chem. Phys. 2016, 18 (38), 26562-26571.

(28) Patra, S.; Sene, S.; Mousty, C.; Serre, C.; Chausse, A.; Legrand, L.; Steunou, N. Design of Laccase-Metal Organic Framework-Based Bioelectrodes for Biocatalytic Oxygen Reduction Reaction. ACS Appl. Mater. Interfaces 2016, 8 (31), 20012-20022.

(29) Bourbonnais, R.; Leech, D.; Paice, M. G. Electrochemical Analysis of the Interactions of Laccase Mediators with Lignin Model Compounds. Biochim. Biophys. Acta 1998, 1379 (3), 381390.

(30) Mohammad-Shiri, H.; Ghaemi, M.; Riahi, S.; Akbari-Sehat, A. Computational and Electrochemical Studies on the Redox Reaction of Dopamine in Aqueous Solution. Int. J. Electrochem. Sci. 2011, 6 (2), 317-336. 
(31) Chang, K. M.; Chang, C. T.; Chan, K. M. Development of an Ion Sensitive Field Effect Transistor Based Urea Biosensor with Solid State Reference Systems. Sensors (Basel) 2010, 10 (6), 6115-6127.

(32) Lee, M.; Lee, J.; Kim, T. H.; Lee, H.; Lee, B. Y.; Park, J.; Jhon, Y. M.; Seong, M. J.; Hong, S. 100 Nm Scale Low-Noise Sensors Based on Aligned Carbon Nanotube Networks: Overcoming the Fundamental Limitation of Network-Based Sensors. Nanotechnology 2010, 21 (5), 055504 .

(33) Freeman, G. B.; Mykytyn, V.; Gibson, G. E. Differential Alteration of Dopamine, Acetylcholine, and Glutamate Release During Anoxia and/or 3,4-Diaminopyridine Treatment. Neurochem. Res. 1987, 12 (11), 1019-1027.

(34) Ozgen, M.; Reese, R. N.; Tulio, A. Z., Jr.; Scheerens, J. C.; Miller, A. R. Modified 2,2Azino-Bis-3-Ethylbenzothiazoline-6-Sulfonic Acid (ABTS) Method to Measure Antioxidant Capacity of Selected Small Fruits and Comparison to Ferric Reducing Antioxidant Power (FRAP) and 2,2'-Diphenyl-1-Picrylhydrazyl (DPPH) Methods. J. Agric. Food. Chem. 2006, 54 (4), 1151-1157.

(35) Mothi, M.; Sampson, S. Pimozide for Schizophrenia or Related Psychoses. Cochrane Database Syst. Rev. 2013, (11), CD001949.

(36) Bai, O.; Wei, Z.; Lu, W.; Bowen, R.; Keegan, D.; Li, X. M. Protective Effects of Atypical Antipsychotic Drugs on Pc12 Cells after Serum Withdrawal. J. Neurosci. Res. 2002, 69 (2), 278-283.

(37) Binda, A. V.; Kabbani, N.; Levenson, R. Regulation of Dense Core Vesicle Release from Pc12 Cells by Interaction between the D2 Dopamine Receptor and Calcium-Dependent Activator Protein for Secretion (Caps). Biochem. Pharmacol. 2005, 69 (10), 1451-1461. 
Figures
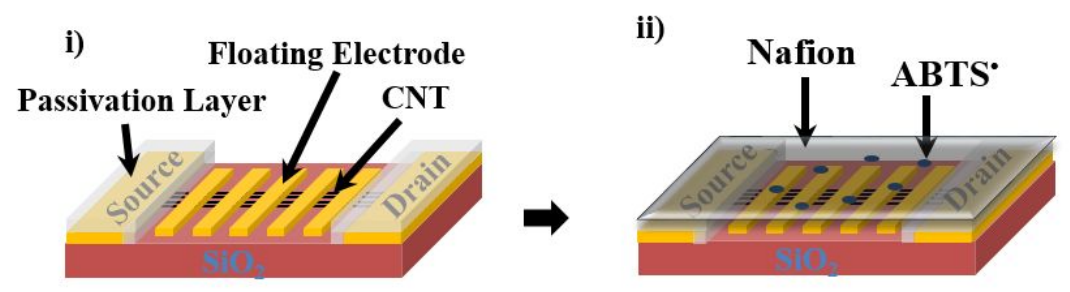

CNT-FET Fabrication

iii)

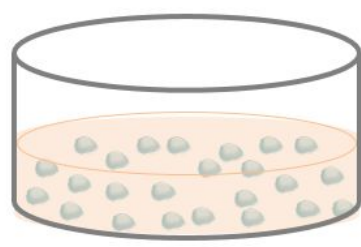

PC12 Cell Culture

Sensor Functionalization

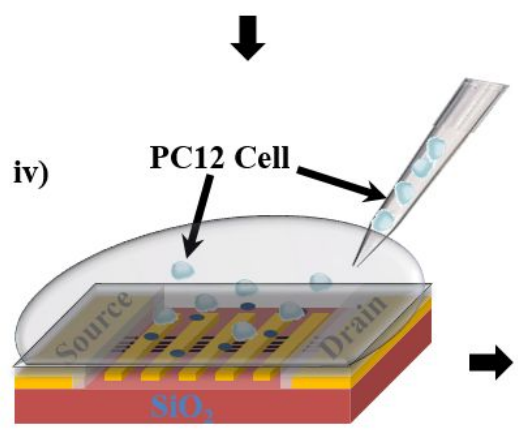

Cell Loading

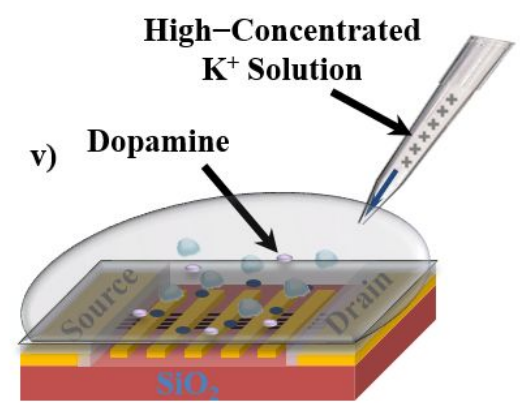

Cell Stimulation

Figure 1. Schematic diagram depicting preparatory processes for the detection of dopamine by using an NRC sensor: (i) fabrication of a conventional CNT-FET device with floating electrodes; (ii) functionalization of the device by a nafion-radical hybrid film to build an NRC sensor; (iii) culturing of PC12 cells in RPMI 1640 medium; (iv) transferring of the cells into the sensor surface; (v) stimulating of the cells by a high-concentrated $\mathrm{K}^{+}$solution and measuring of dopamine release by using the sensor. This sensor can selectively respond to dopamine released from living PC12 cells. The drawing is not to scale. 

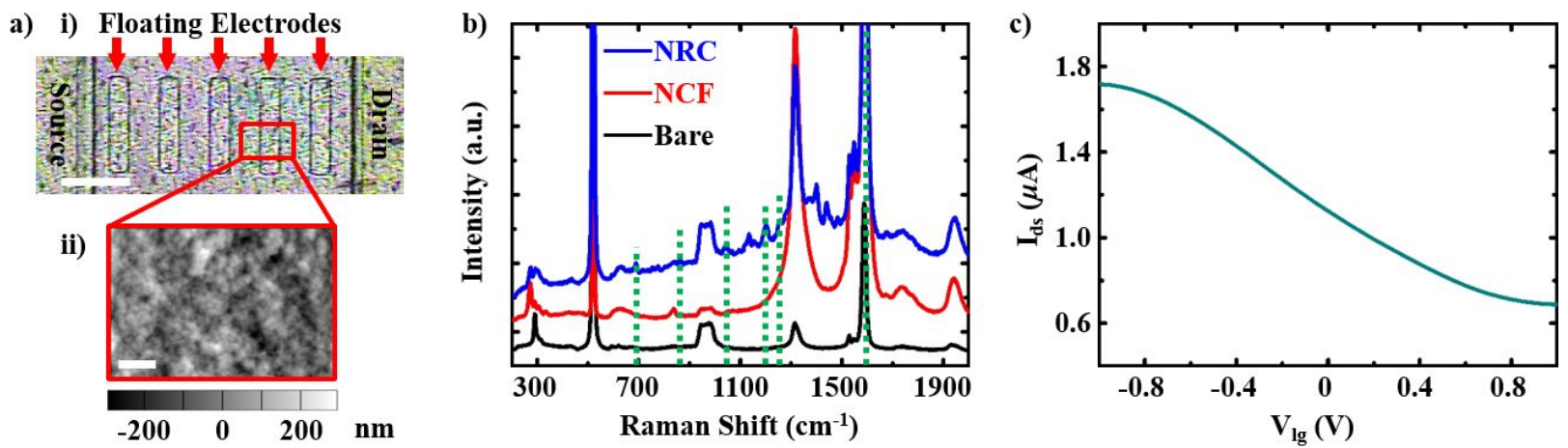

Figure 2. Characterization of a nafion-radical hybrid film on a floating electrode-based carbon nanotube sensor. (a) Optical image (i) and AFM topography image (ii) of an NRC sensor which has five floating electrodes. Each individual floating electrode had the dimension of $10 \mu \mathrm{m} \times 60$ $\mu \mathrm{m}$. The AFM image taken in a tapping mode shows the uniform surface of a sensing area. The scale bars represent $40 \mu \mathrm{m}$ (i) and $5 \mu \mathrm{m}$ (ii). (b) Raman spectra of the CNT regions of an NRC sensor (marked by "NRC") and two different CNT-FET devices: a floating electrode-based CNT-FET device coated with a nafion layer (marked by "NCF") and a bare floating electrodebased CNT-FET device (marked "Bare"). The Raman spectrum of the NRC sensor exhibits characteristic peaks of $\mathrm{ABTS}^{\bullet}$ radicals at the wavelengths of $690,862,1046,1201,1255$ and $1592 \mathrm{~cm}^{-1}$ (marked by green dotted lines). (c) Liquid gating effect of an NRC sensor measured in a phosphate buffer. A gate bias was swept from $-1 \mathrm{~V}$ to $1 \mathrm{~V}$ while a source-drain bias voltage was maintained at $0.1 \mathrm{~V}$. 

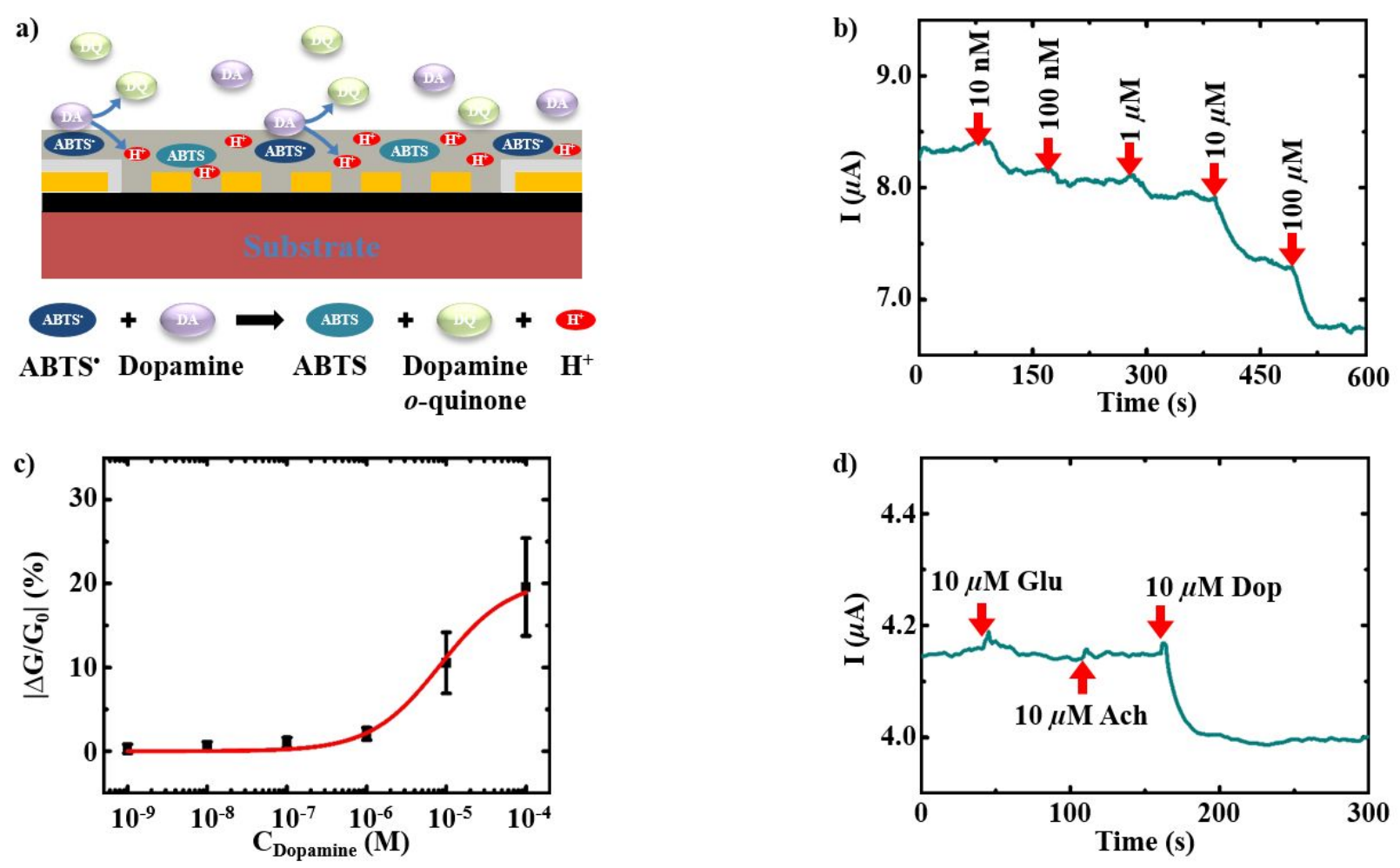

Figure 3. Responses of NRC sensors to the presence of dopamine solutions. (a) Mechanism of dopamine sensing using an NRC sensor. Once dopamine molecules react with $\mathrm{ABTS}^{\bullet}$ radicals in a nafion film on the sensor, the formation of hydrogen ions $\left(\mathrm{H}^{+}\right)$induces a positive field effect on the underlying CNTs. (b) Real-time electrical current measurement of an NRC sensor during the additions of dopamine solutions with different concentrations ranging from $1 \mathrm{nM}$ to $100 \mu \mathrm{M}$. A source-drain bias voltage of $0.1 \mathrm{~V}$ was maintained during electrical measurements. (c) Dosedependent responses of NRC sensors to various concentrations of dopamine. We repeated sensing measurements for five different NRC sensors to confirm the reliability. Data are expressed as means \pm SEM (standard error of the mean), $(n=5)$. (d) Real-time responses of an NRC sensor to different neurotransmitters such as Glutamate (Glu), Acetylcholine (Ach), and Dopamine (Dop). The drastic change of currents was observed only when a dopamine solution was added. 
a)
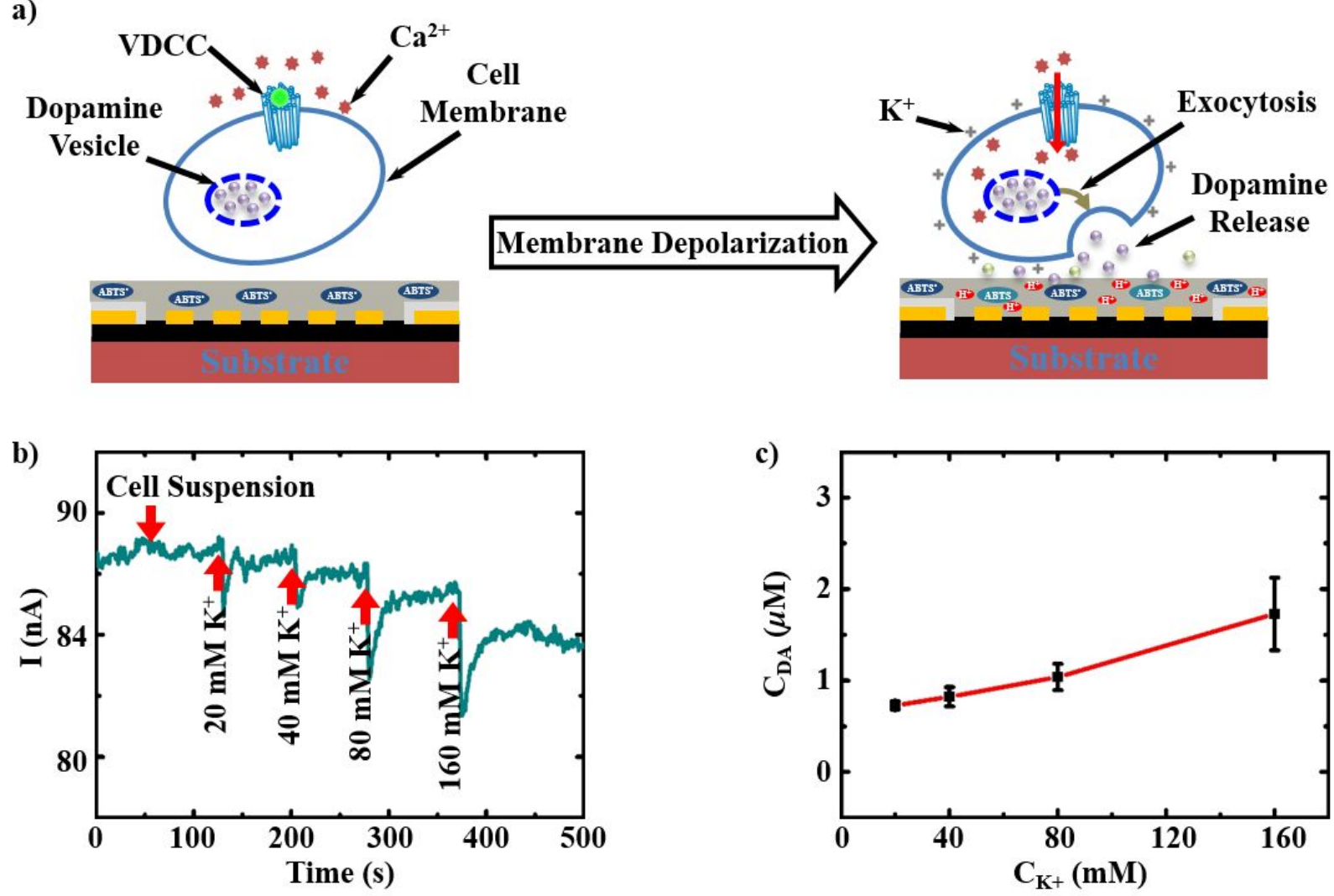

Figure 4. Quantitative monitoring of dopamine release from living $\mathrm{PC} 12$ cells under the stimulation of $\mathrm{K}^{+}$solutions. (a) Schematic diagram showing the mechanism of dopamine release from $\mathrm{PC} 12$ cells stimulated by a high-concentrated $\mathrm{K}^{+}$solution and the real-time monitoring of the dopamine release by an NRC sensor. (b) Real-time current changes measured by an NRC sensor during the additions of a cell suspension solution and $\mathrm{K}^{+}$solutions at various concentrations. The significant reduction of currents was observed on the additions of $\mathrm{K}^{+}$ solutions containing $2.5 \mathrm{mM} \mathrm{Ca}^{2+}$. (c) Dose-response curve for the stimulation of different $\mathrm{K}^{+}$ solutions on dopamine release from PC12 cells. The concentrations of dopamine were calculated from the relative conductance changes of sensors by using the Langmuir thermal equation (eq 1). Data are expressed as means $\pm \operatorname{SEM}(n=5)$. 
a)

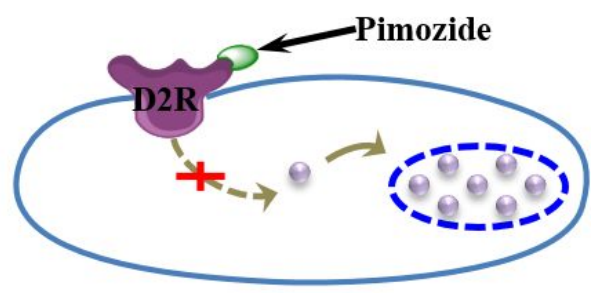

Figure 5. Evaluation of the effects of pimozide on $\mathrm{K}^{+}$-evoked dopamine release from PC12 cells. (a) Schematic drawing depicting the mechanism about the effect of pimozide on the dopamine synthesis in PC12 cells. (b) $\mathrm{K}^{+}$-evoked dopamine release from $\mathrm{PC} 12$ cells pretreated with pimozide. The cells were pretreated with pimozide at different concentrations in the range of $0.01-10 \mu \mathrm{M}$ for $24 \mathrm{~h}$, followed by the stimulation of $80 \mathrm{mM} \mathrm{K}^{+}$solutions. Pimozide reduced the production and secretion of dopamine in the cells. The bars indicate means \pm SEM. 


\section{TOC Graphic}

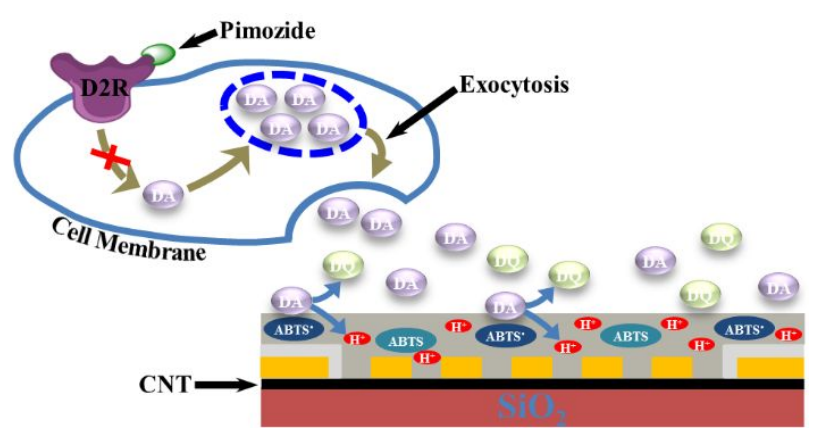

For Table of Contents Only 